Check for updates

Cite this: RSC Adv., 2019, 9, 15190

\title{
Vesicular self-assembly of a natural ursane-type dihydroxy-triterpenoid corosolic acid $\dagger$
}

\author{
Braja G. Bag, (D) * Chhabi Garai and Subrata Ghorai \\ Corosolic acid, a natural ursane-type 6-6-6-6-6 pentacyclic dihydroxy triterpenic acid, is a well known \\ antidiabetic compound extractable from leaves of Psidium guajava. In this manuscript we have reported the \\ self-assembly properties of corosolic acid in different liquids. The compound undergoes self-assembly to \\ give vesicular morphology in different aqueous organic liquids. Supramolecular gels were also obtained in \\ some aqueous binary liquids such as ethanol-water and dimethyl formamide-water. The morphology of \\ the self-assemblies of corosolic acid were characterized by using different microscopic techniques like \\ optical microscopy, field emission scanning electron microscopy, transmission electron microscopy, \\ atomic force microscopy as well as XRD and FTIR studies. We also demonstrated the application of \\ vesicular self-assemblies for the entrapment and release of fluorophores including an anticancer drug.
}

Received 13th April 2019

Accepted 7th May 2019

DOI: 10.1039/c9ra02801c

rsc.li/rsc-advances
One of the most interesting observation in the self-assembly of triterpenoids is that, minute variation in the triterpenoid backbone as well as the functional groups often lead to different morphology in liquids. For example, the monohydroxy triterpenic acids betulinic acid yields gel in organic liquids via fibrillar networks but oleanolic acid yields gels via mostly vesicular self-assembly. ${ }^{37,39}$ Literature search reveals that through the self-assembly of a few oleanane type 6-6-6-6-6 triterpenoids have been reported, the self-assembly of ursane type triterpenoid are rare. ${ }^{50,51}$ Corosolic acid, a natural 6-6-6-6-6 pentacyclic ursanetype triterpenoid is extractable from the leaves of Psidium guajava (Fig. 1). This compound contains extraordinary antidiabetic property ${ }^{52,53}$ along with anticancer activity. ${ }^{54,55}$ Presence of two hydroxy groups at one end and the carboxy group at the other end with a ursane-type triterpene skeleton providing hydrophobic backbone makes it an interesting amphiphile for the study of its self-assembly properties in different liquids. Herein we report the first self-assembly properties of corosolic acid in liquids. The ursane-type dihydroxy triterpenoid formed vesicular selfassembly in all the aqueous binary liquid mixtures studied yielding gels at higher concentrations. The morphology of the self-assemblies was characterized by optical, electron and atomic force microscopic techniques and X-ray diffraction studies. Entrapment of fluorophores inside the vesicular self-assemblies and their subsequent release has also been demonstrated.

\section{Results and discussion}

Corosolic acid $\mathbf{1}$ was obtained by solvent extraction of the powdered matured leaves of Psidium guajava followed by purification of the crude extract by column chromatography (see Experimental section). It is a rigid molecule containing fused 66-6-6-6 pentacyclic ursane-type hydrocarbon backbone along 


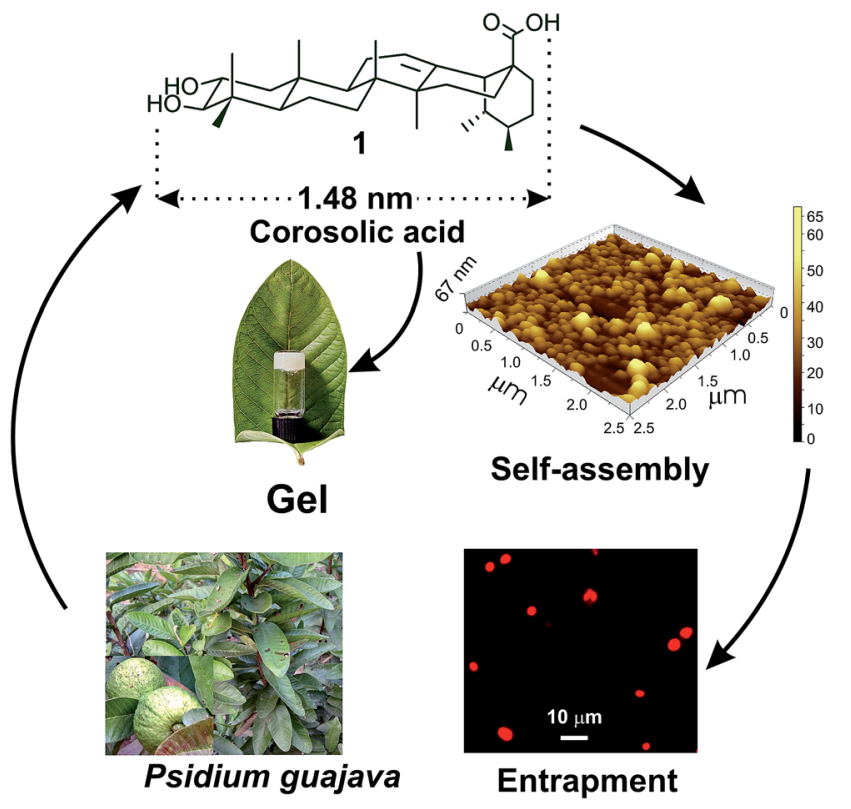

Fig. 1 Schematic representation of self-assembly of corosolic acid 1 , extracted from Psidium guajava yielding vesicular morphology and its use in drug entrapment.

with two hydroxyl groups at 2- and 3-positions and one carboxyl group at the 28-position. Energy minimized structures of the molecule obtained by both DFT method ${ }^{56}$ (Fig. 2) and Allinger's MMX algorithm ${ }^{57}$ revealed the molecular length as $1.48 \mathrm{~nm}$ (Fig. S1and S2 ESI†े).

\subsection{Study of self-assembly properties}

Corosolic acid $\mathbf{1}$ was insoluble in water or in common organic solvents like chloroform, dichloromethane but soluble in polar solvents like DMSO, DMF, THF, ethanol, etc. This solubility behaviour might be due to the presence of rigid hydrocarbon backbone and several polar groups at the extreme ends of the molecule. A hot clear solution of compound $1(2 \mathrm{mg})$ in DMSO $(50 \mu \mathrm{L})$ on treatment with water $(50 \mu \mathrm{L})$ followed by cooling at room temperature became cloudy. The mixture was re-dissolved by heating and kept at room temperature and observed visually after 6 h. A viscous colloidal suspension was observed visually. Similarly, self-assembly of $\mathbf{1}$ was carried out in ethanol-water, DMF-water and THF-water (Table 1). Opaque gels were obtained in DMF-water and ethanol-water and colloidal suspension was obtained in THF-water.

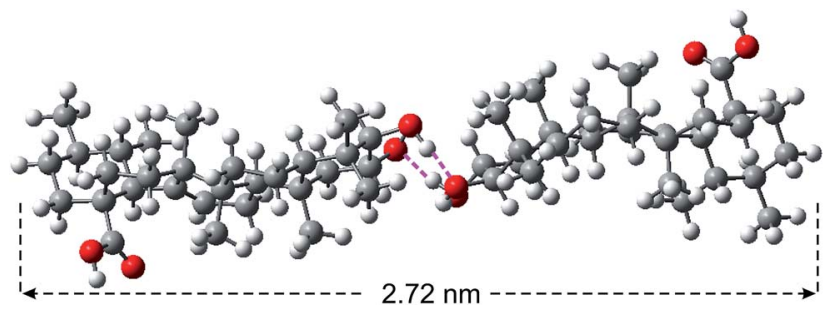

Fig. 2 Energy minimized structure of corosolic acid dimer (held together by $\mathrm{H}$-bonding) obtained by DFT calculation.
Table 1 Self-assembly of corosolic acid 1

\begin{tabular}{lllll}
\hline Entry & Solvent & State $^{a}$ & MGC $^{b}$ & $T_{\text {gel }}{ }^{c}\left({ }^{\circ} \mathrm{C}\right)$ \\
\hline 1 & DMSO-water(1:1) & CS & 46.1 & - \\
2 & THF-water $(1: 1)$ & CS & 34.9 & - \\
3 & DMF-water $(2: 1)$ & G & 20.5 & 51 \\
4 & Ethanol-water $(2: 1)$ & G & 18.6 & 48
\end{tabular}

${ }^{a} \mathrm{G}=$ gel, $\mathrm{CS}=$ colloidal suspension. ${ }^{b} \mathrm{MGC}=$ minimum gelator concentration (mM). ${ }^{c} T_{\text {gel }}=$ gel to sol transition temperatures at MGC.

\subsection{Study of the morphology of the self-assemblies}

The morphologies were characterized by different techniques like optical microscopy, field emission scanning electron microscopy (FESEM), atomic force microscopy (AFM), high resolution transmission electron microscopy (HRTEM), X-ray diffraction (XRD) and FTIR studies.

AFM study of 1 carried out with the dried self-assemblies of 1 in DMF-water $(2: 1,1.69 \mathrm{mM})$ revealed the formation of closely packed spherical self-assemblies (Fig. 3a and b) of 38-154 nm diameters with average size $90.32 \mathrm{~nm}$ calculated from 150 spheres (Fig. S3 ESI $\dagger$ ) and heights $20-60 \mathrm{~nm}$. The 3D image confirms spherical nature of the self-assemblies. Similarly AFM study of 1 in ethanol-water $(2: 1,1.69 \mathrm{mM})$ also indicated the generation of spherical self-assemblies (Fig. S4 ESI $\dagger$ ). The measured heights of spherical self-assemblies were smaller
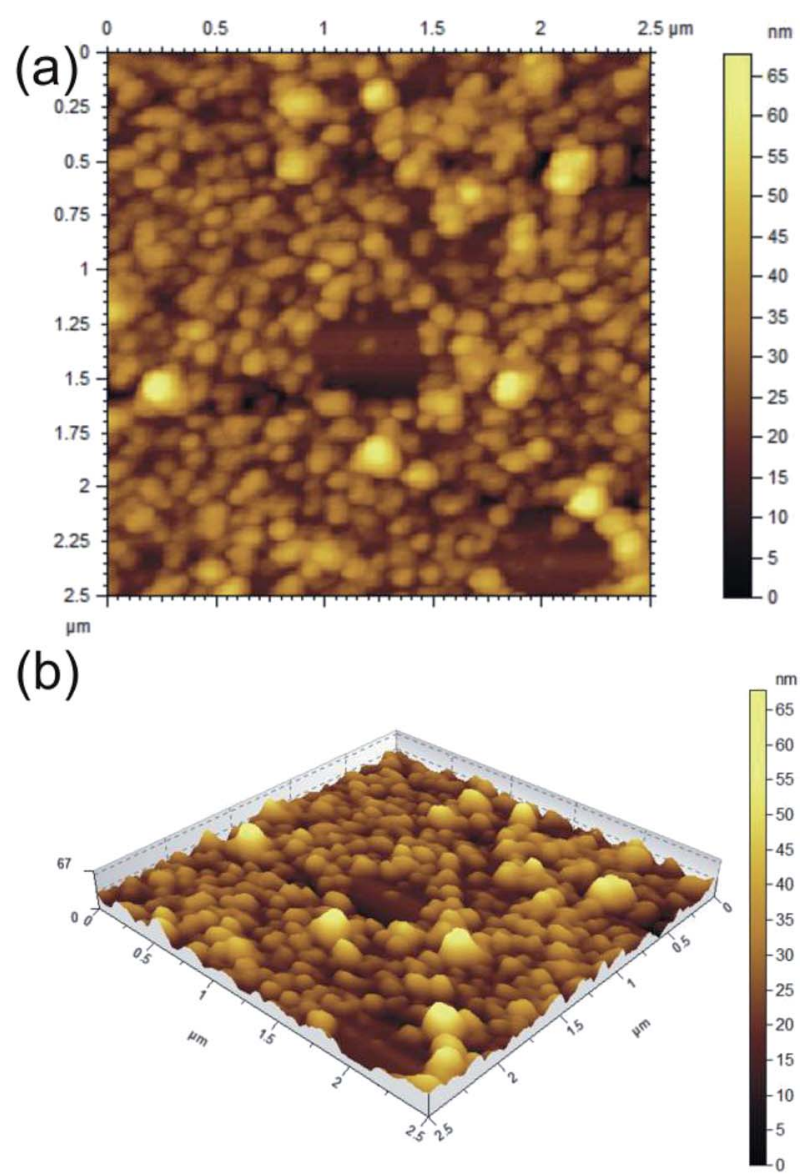

Fig. 3 AFM images (a: 2D, b: 3D) of dried self assemblies of corosolic acid in DMF-water (2:1, $1.69 \mathrm{mM})$. 
compared to their radii due to distortion by the AFM tip. This observation also supported that the spherical morphologies were soft in nature. ${ }^{58}$

FESEM studies of dried self-assemblies of $1(4.23 \mathrm{mM})$ prepared from ethanol-water $(3: 1)$ clearly indicated the formation of densely packed spherical morphologies (Fig. 4a-d) having diameter 300-900 nm calculated from 150 spheres and average diameter $580 \mathrm{~nm}$ (Fig. S5 ESI $\dagger$ ).

Optical microscopy study was carried out by placing the colloidal sample on a glass slide covered with cover slip for reducing the evaporation of liquid. Optical microscopy studies revealed that micro sized densely packed spherical morphologies were formed by self-assembly of 1 in DMSO-water $(1: 1$, $46.15 \mathrm{mM})$, THF-water $(1: 1,34.9 \mathrm{mM})$ and ethanol-water (3:1, $46.1 \mathrm{mM}$ ) (Fig. 5). The average diameter of the spherical self-assemblies were 2.0-2.6 $\mu \mathrm{m}$ (Fig. S6 and S7 ESI $\dagger$ ).

To get further insight into the spherical morphologies, HRTEM study was carried out with the dried self-assemblies of 1 from the colloidal suspensions in DMF-water (2:1, $3.1 \mathrm{mM})$. Dark spherical objects observed in the HRTEM images indicated the formation of soft-vesicles (Fig. 6). ${ }^{\mathbf{5 9 , 6 0}}$ Spherical objects with distinct membrane structure were also observed confirming the vesicular nature of the self-assemblies (Fig. $6 \mathrm{~b}$ and $\mathrm{c}$ ). The thickness of the membrane observed by HRTEM was $2.72 \mathrm{~nm}$ (Fig. 6c). This matches with the length $(2.72 \mathrm{~nm})$ of the
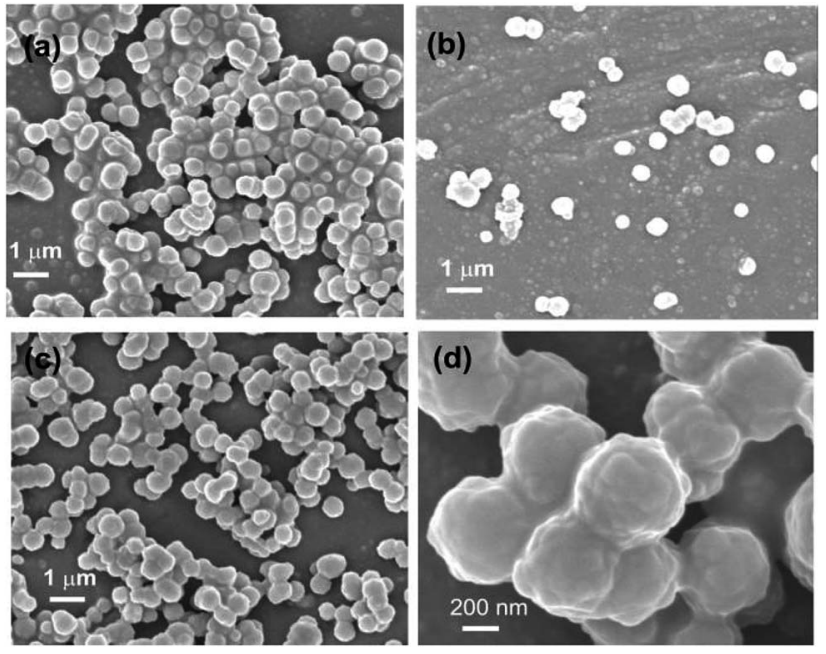

Fig. 4 (a-d) FESEM images of a dry self-assemblies prepared from CA in $\mathrm{EtOH}$-water $(3: 1,4.23 \mathrm{mM})$.
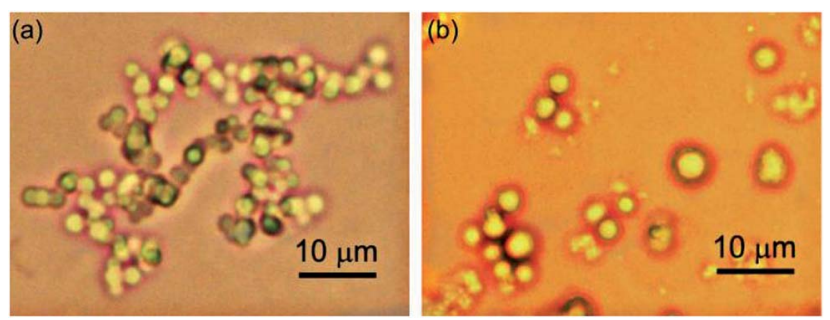

Fig. 5 Optical microscopy images of self-assemblies prepared from CA in (a) DMSO-water (1 : 1, 46.15 mM), (b) THF-water (1 : 1, 34.9 mM).

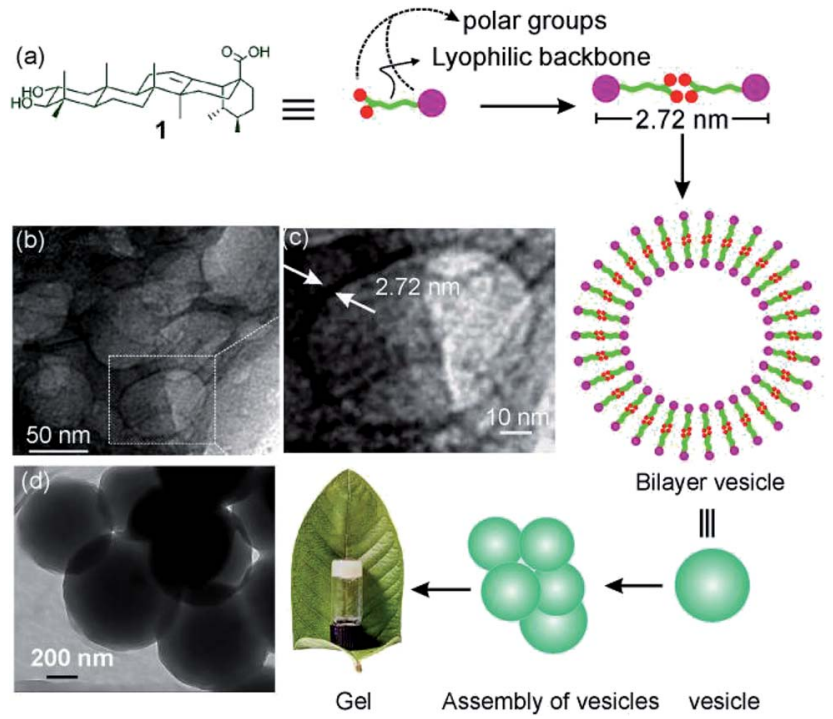

Fig. 6 (a) Schematic presentation of bilayer vesicle formation, (b, c, d) HRTEM images of self-assemblies prepared from 1 in DMF-water $(2: 1,3.1 \mathrm{mM})$.

H-bonded dimer of corosolic acid obtained by energy minimization (Fig. 2). The vesicular bilayer morphology was also supported by $2 \theta=3.25^{\circ}$ peak in X-ray diffraction studies of colloidal sample in DMF-water corresponding to a $d$ spacing of $2.72 \mathrm{~nm}$ (Fig. S8 ESI $\dagger$ ). A schematic representation for the formation of gel via bilayer vesicular self-assembly is given in Fig. 6 .

The self-assembly process is generally driven by non-covalent interactions like H-bonding among the hydroxyl groups and also the van der Waals interactions with the triterpenoid backbones. We have carried out FTIR studies and compared the FTIR spectra of dried self-assemblies produced from DMFwater and ethanol-water with the neat powder of $\mathbf{1}$. The ' $\mathrm{O}-\mathrm{H}$ ' stretching frequency of the powder sample appeared at $3379 \mathrm{~cm}^{-1}$ whereas that from the dried self-assemblies obtained from DMF-water and ethanol-water appeared at 3311 and $3344 \mathrm{~cm}^{-1}$ respectively (Fig. S9 ESI $\dagger$ ). But there was no significant change of the ' $\mathrm{C}=\mathrm{O}$ ' stretching frequency for the powder sample and the dried self-assemblies. Hence, the decrease in the "O-H" stretching frequencies of the dried selfassemblies compared to that in the powder sample might to be attributed to the intermolecular $\mathrm{H}$-bonding among the ' $\mathrm{O}-\mathrm{H}$ ' groups.

\subsection{Thermo-reversibility of gels of corosolic acid in DMF- water and ethanol-water}

Since the gels derived from corosolic acid were thermally reversible, we plotted $T_{\text {gel }}$ against the gelator concentration (mM) to investigate the thermodynamic parameters. The $T_{\text {gel }}$ value increased with increase in the gelator concentration indicating that stronger intermolecular interactions are present at higher concentrations of gelator. In ethanol-water $(2: 1)$, the $T_{\text {gel }}$ value at minimum gelator concentration (MGC, $18.6 \mathrm{mM}$ ) was $48{ }^{\circ} \mathrm{C}$ and increased to $78{ }^{\circ} \mathrm{C}$ (Fig. 7a) at concentration 45.2 mM. Similarly, the $T_{\text {gel }}$ value in DMF-water (2:1) at MGC (20.5 mM) was $51{ }^{\circ} \mathrm{C}$ and increased to $70{ }^{\circ} \mathrm{C}$ (Fig. 7b) at 


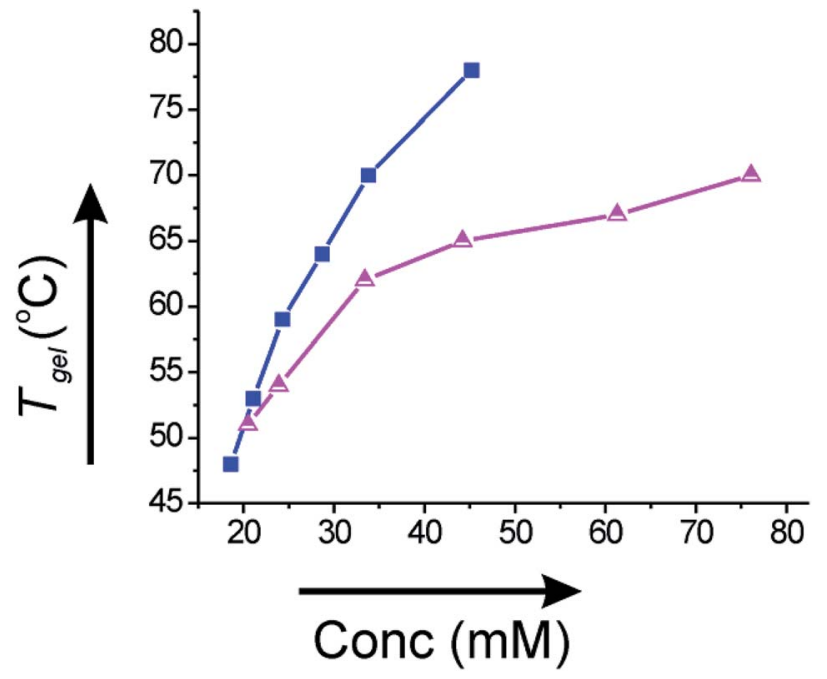

Fig. 7 Plot of $T_{\text {gel }}$ Vs. concentration (mM) of 1 in (a) $2: 1$ ethanol-water (- - -) and (b) 2 : 1 DMF-water (- $\Delta-)$.

Table 2 Thermodynamic parameters $\left(\Delta H^{\circ}, \Delta S^{\circ}, \Delta G^{\circ}\right)$ for gel to sol transition of gels of corosolic acid 1 in different liquids at $298 \mathrm{~K}$

\begin{tabular}{llcl}
\hline Liquid & $\Delta H^{\circ}\left(\mathrm{kJ} \mathrm{mol}^{-1}\right)$ & $\Delta S^{\circ}\left(\mathrm{J} \mathrm{mol}^{-1} \mathrm{~K}^{-1}\right)$ & $\Delta G^{\circ}\left(\mathrm{kJ} \mathrm{mol}^{-1}\right)$ \\
\hline Ethanol-water & 27.336 & 51.55 & 11.97 \\
DMF-water & 65.64 & 168.95 & 15.29
\end{tabular}

concentration $76.1 \mathrm{mM}$. The plot of $T_{\text {gel }} v s$. gelator concentration allowed us to evaluate the thermodynamic parameters $\left(\Delta H^{\circ}, \Delta S^{\circ}, \Delta G^{\circ}\right)$ at $298 \mathrm{~K}$ (Table 2$)$. The positive value of Gibbs free energy change indicated that gel to sol transformation is thermodynamically unfavorable and the gels were highly stable.

\subsection{Entrapment of fluorophores inside the vesicular self- assemblies}

Vesicular self-assemblies have drawn great attention in last decade in biomedical applications as nano carriers for entrapment and controlled release of drugs into the targeted cell. ${ }^{61-63}$
The vesicular morphologies produced by renewable non toxic amphiphilic molecules are interesting candidates as carriers of chemotherapeutic drugs due to their in general biocompatible nature with minimum side-effects. ${ }^{64-68}$

Different microscopic images revealed that self-assembly of corosolic acid lead to the formation of vesicular morphologies. To investigate the capability of vesicular assemblies towards entrapment of fluorophores, we attempted to entrap the cationic fluorophore rhodamine $\mathrm{B}(0.02 \mathrm{mM})$ inside the vesicular self-assemblies of 1 in ethanol-water (3:1, $9.8 \mathrm{mM})$. The bright spherical fluorescent images under epifluorescent microscope (Fig. 8) clearly indicated the entrapment of Rho-B inside the spherical self-assemblies of 1 . Then we investigated the entrapment of the anionic fluorophore 5,6-carboxyfluorescein (CF) (0.42 mM) inside the self-assemblies of 1 in ethanol-water $(3: 1,21.15 \mathrm{mM})$ which also indicated the entrapment of CF into the vesicular self-assemblies (Fig. 8a). These observations inspired us to examine the entrapment of the anticancer drug doxorubicin $(0.46 \mathrm{mM})$ into the vesicular self-assemblies of 1 in ethanol-water ( $3: 1,23.27 \mathrm{mM})$. In this case also, the epifluorescent microscopy images revealed that the drug was encapsulated inside the vesicular assemblies (Fig. 8c).

Fluorescence emission spectroscopy study further confirmed the entrapment of Rho-B into vesicular self-assemblies of $\mathbf{1}$. The fluorescence emission intensity $\left(\lambda_{\mathrm{ex}} 576 \mathrm{~nm}\right)$ of free Rho-B was quenched after the addition of corosolic acid (Fig. S10 ESI $\dagger$ ). This is due to the entrapment of Rho-B inside the vesicular selfassemblies of corosolic acid with concomitant decrease in the emission intensity of Rho-B arising due to self-quenching.

\subsection{Study of release of fluorophores by rupture of vesicles}

Triton X-100, a non-ionic surfactant containing a branched chain octylphenyl group attached with a polyoxyethylene long chain. It is generally utilized to isolate membrane protein complexes and also as lysing agent to release intracellular materials. ${ }^{69-71}$ When the vesicular self-assemblies of 1 loaded with Rho-B was treated with Triton X-100, the disruption of vesicular assemblies was observed (Fig. 9) under epifluorescent microscope.
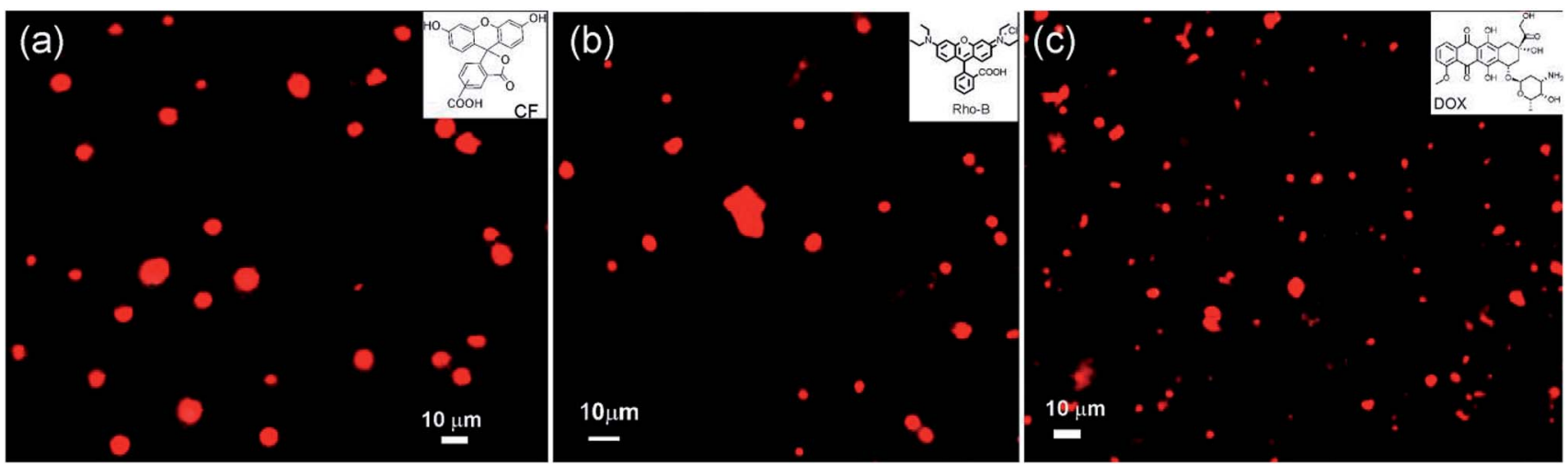

Fig. 8 Epifluorescent microscopy images (a) entrapped CF (21.15 mM CA and 0.42 mM CF), (b) entrapped Rho-B (9.8 mM CA and 0.02 mM RhoB) and (c) entrapped DOX (23.27 mM CA and $0.46 \mathrm{mM} \mathrm{DOX)} \mathrm{into} \mathrm{corosolic} \mathrm{acid} \mathrm{in} \mathrm{ethanol-water}(3: 1)$. 

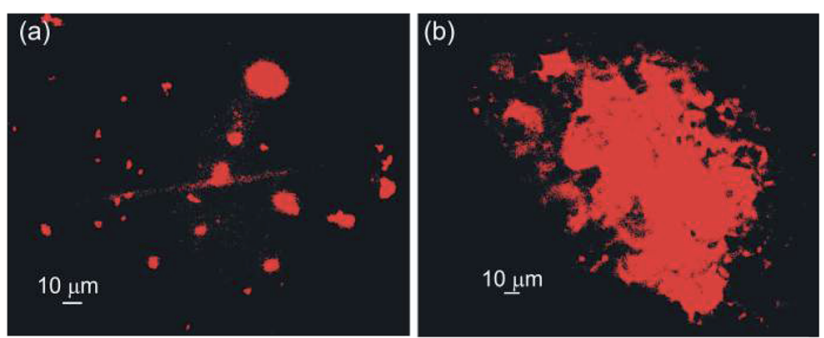

Fig. 9 Epifluorescent microscopy images of Rho-B loaded selfassemblies of corosolic acid in ethanol-water ( $3: 1)$ : (a) before and (b) after the treatment of Triton-X 100.

\section{Conclusions}

In conclusion, first self-assembly of a natural ursane-type dihydroxy triterpenoid corosolic acid has been reported. To our knowledge, this is also the first report of vesicular selfassembly and gel of a ursane-type dihydroxy triterpenoid in aqueous binary liquids. Optical, electron and atomic force microscopic studies followed by X-ray diffraction studies supported the formation of a bilayer vesicular morphology. The energy minimized structure of corosolic acid dimer held together by H-bonding among the hydroxyl groups of corosolic acids carried out by DFT calculation also supported the bilayer vesicular self-assembly. The vesicular assemblies could successfully entrap fluorophores including the chemotherapeutic drug doxorubicin. Release of the entrapped fluorophore was also demonstrated via rupture of vesicles making the self-assemblies useful for targeted drug delivery.

\section{Experimental}

\subsection{Isolation of corosolic acid 1}

Matured leaves of Psidium guajava were air dried and finely powdered using a grinder. The powdered leaves $(60 \mathrm{~g})$ was suspended in ethyl acetate $(400 \mathrm{~mL})$ and stirred magnetically for $10 \mathrm{~h}$ and then filtered. The residue was soaked again in ethyl acetate $(300 \mathrm{~mL})$ and refluxed for $2 \mathrm{~h}$, cooled and filtered. The crude product $(4.0 \mathrm{~g})$ obtained after removal of the volatiles was purified repeated column chromatography (Si-gel) using 10$50 \%$ ethyl acetate as the eluent followed by decolorization on treatment with charcoal to yield corosolic acid as colorless solid $(0.2 \mathrm{~g}, 0.3 \%$ yield $)$ solid. $\mathrm{MP}=248-253{ }^{\circ} \mathrm{C}$. $R_{\mathrm{f}}: 0.61$, ethyl acetate-dichloromethane (1:1). ${ }^{1} \mathrm{H}$ NMR (400 MHz, DMSO-d $\left.{ }^{6}\right)$ $\delta: 5.14(1 \mathrm{H}), 4.41-4.34(1 \mathrm{H}, \mathrm{m}), 2.73(1 \mathrm{H}, \mathrm{d}, J=7.2 \mathrm{~Hz}), 2.5(1 \mathrm{H}$, s), $2.1(\mathrm{H}-18, \mathrm{~d}, J=11 \mathrm{~Hz}), 1.98-1.15$ (triterpenoid protons), 1.08 (3H, S), 1.01 (3H, d), 0.91 (3H, s), 0.87 (3H, s), $0.82(3 \mathrm{H}, \mathrm{d}), 0.73$ $(3 \mathrm{H}, \mathrm{s}), 0.70(3 \mathrm{H}, \mathrm{s}) .{ }^{13} \mathrm{C}$ NMR $\left(100 \mathrm{MHz}, \mathrm{DMSO}-\mathrm{d}^{6}\right) \delta: 178.77$, 138.7, 124.94, 82.73, 67.64, 55.18, 52.84, 47.5, 47.44, 47.3, 45.91, $42.15,41.23,39.89,39.4,38.87,38.02,36.77,33.08,30.62,29.27$, $27.94,24.24,23.7,23.4,21.52,18.47,17.62,17.45$, 16.86. FTIR $\left(\mathrm{KBr}, \mathrm{cm}^{-1}\right.$ ): 3379 (w), 2923 (s), 1689 (s), 1458 (s), 1453 (s), 1376 (s), 1051 (s). MS (EI): calculated for $\mathrm{C}_{30} \mathrm{H}_{48} \mathrm{O}_{4} 472.4$, found 472.4.

\subsection{Self-assembly studies}

Typically, corosolic acid ( $2 \mathrm{mg})$ was weighed in a vial $(1 \mathrm{~cm}$ id) and dissolved in an organic solvent $(50-100 \mu \mathrm{L})$ by heating with magnetic stirring. Then distilled water $(20-40 \mu \mathrm{L})$ was added to the hot solution dropwise until cloudiness appeared. Then the mixture was re-dissolved by heating and then allowed to cool at room temperature under sealed condition. The formation of gel was examined visually by turning the vial upside down after $6 \mathrm{~h}$. No gravitational flow of the material indicated the formation of a gel.

\section{Conflicts of interest}

There are no conflicts to declare.

\section{Acknowledgements}

We thank SERB (EMR/2016/001123), Indo-Srilanka (DST/INT/ SL/P25/2016), DST-FIST, UGC-SAP and Vidyasagar University for financial and infrastructural support. CG thanks UGC and SG thanks CSIR for research fellowships.

\section{Notes and references}

1 E. Carretti, M. Bonini, L. Dei, B. H. Berrie, L. V. Angelova, P. Baglioni and R. G. Weiss, Acc. Chem. Res., 2010, 43, 751760.

2 R. G. Weiss and P. Terech, in Molecular Gels: Materials with Self-Assembled Fibrillar Networks, Springer, Dordrecht, 2006.

3 S. Bhattacharya and S. K. Samanta, Chem. Rev., 2016, 116, 11967-12028.

4 C. Wang, Z. Wang and X. Zhang, Acc. Chem. Res., 2012, 45, 608-618.

5 D. S. Guo and Y. Liu, Acc. Chem. Res., 2014, 47, 1925-1934.

6 R. Dong, Y. Zhou and X. Zhu, Acc. Chem. Res., 2014, 47, 20062016.

7 M. B. Avinash and T. Govindaraju, Acc. Chem. Res., 2018, 51, 414-426.

8 J. Zhou, G. Yu and F. Huang, Chem. Soc. Rev., 2017, 46, 70217053.

9 Z. A. Ahmady and K. Kostarelos, Chem. Rev., 2016, 116, 38833918.

10 B. Chen, X. Y. He, X. Q. Yi, R. X. Zhuo and S. X. Cheng, ACS Appl. Mater. Interfaces, 2015, 7, 15148-15153.

11 D. Kuciauskas and G. A. Caputo, J. Phys. Chem. B, 2009, 43, 14439-14447.

12 M. Waqas, W. Jeong, Y. Joo Lee, D. H. Kim, C. Ryou and Y. B. Lim, Biomacromolecules, 2017, 18, 943-950.

13 Y. Zimenkov, S. N. Dublin, R. Ni, R. S. Tu, V. Breedveld, R. P. Apkarian and V. P. Conticello, J. Am. Chem. Soc., 2006, 21, 6770-6771.

14 Y. Cote, I. W. Fu, E. T. Dobson, J. E. Goldberger, H. D. Nguyen and J. K. Shen, J. Phys. Chem. C, 2014, 118, 16272-16278. 
15 Y. Huang, Y. Mai, X. Yang, U. Beser, J. Liu, F. Zhang, D. Yan, K. Müllen and X. Feng, J. Am. Chem. Soc., 2015, 137, 1160211605.

16 Y. L. Zhao, I. Aprahamian, A. Trabolsi, N. Erina and J. F. Stoddart, J. Am. Chem. Soc., 2008, 130, 6348-6350.

17 J. H. Jung, Y. Ono and S. Shinkai, Angew. Chem., Int. Ed., 2000, 39, 1862-1865.

18 M. Zinic, F. Vogtle and F. Fages, Top. Curr. Chem., 2005, 256, 39-76.

19 A. Ajayaghosh, C. Vijayakumar, R. Varghese and S. J. George, Angew. Chem., Int. Ed., 2006, 45, 456-460.

20 K. Sugiyasu, N. Fujita and S. Shinkai, Angew. Chem., Int. Ed., 2004, 43, 1229.

21 J. Yan, J. Liu, P. Jing, C. Xu, J. Wu, D. Gao and Y. Fang, Soft Matter, 2012, 8, 11697-11703.

22 B. Shi, P. Zhang, T. Wei, H. Yao, Q. Lin and Y. Zhang, Chem. Commun., 2013, 49, 7812-7814.

23 K. Y. Lee and D. J. Monney, Chem. Rev., 2001, 101, 18691879.

24 E. Gazit, Chem. Soc. Rev., 2007, 36, 1263-1269.

25 A. Barnard, P. Psocco, S. Pricl, M. Calderon, R. Hagg, M. E. Hwang, V. W. T. Shum, D. W. Pack and D. K. Smith, J. Am. Chem. Soc., 2011, 133, 20288-20294.

26 B. G. Bag, S. Ghorai, S. K. Panja, S. K. Dinda and K. Paul, RSC Adv., 2018, 8, 29155-29163.

27 B. G. Bag, C. Garai, R. Majumdar and M. Laguerre, Struct. Chem., 2012, 23, 393-398.

28 S. Grassi, E. Carretti, L. Dei, C. W. Branham, B. Khar and R. G. Weiss, New J. Chem., 2011, 35, 445-452.

29 A. Ajayaghosh, R. Varghese, S. Mahesh and V. K. Praveen, Angew. Chem., Int. Ed., 2006, 45, 3261-3264.

$30 \mathrm{~S}$. Bhattacharya and S. Ghanashyam Acharya, Langmuir, 2000, 16, 87-97.

31 D. Ke, C. Zhan, A. D. Q. Li and J. Yao, Angew. Chem., Int. Ed., 2011, 50, 3715-3719.

32 W. Cai, G. T. Wang, Y. X. Xu, X. K. Jiang and Z. T. Li, J. Am. Chem. Soc., 2008, 130, 6936.

33 M. Zhang, L. Meng, X. Cao, M. Jiang and T. Yi, Soft Matter, 2012, 8, 4494-4498.

34 P. A. Wilbon, F. Chu and C. Tang, Macromol. Rapid Commun., 2013, 34, 8-37.

35 A. Gandini, Green Chem., 2011, 13, 1061-1083.

36 B. G. Bag and R. Majumdar, RSC Adv., 2014, 4, 53327-53334. 37 B. G. Bag and S. S. Dash, Nanoscale, 2011, 3, 4564-4566.

38 B. G. Bag and S. S. Dash, Langmuir, 2015, 31, 13664-13672.

39 B. G. Bag and K. Paul, Asian J. Org. Chem., 2012, 1, 150-154.

40 B. G. Bag and R. Majumdar, RSC Adv., 2012, 2, 8623-8626.

41 N. He, K. Zhi, X. Yang, H. Zhang and J. Wang, New J. Chem., 2018, 42, 14170-14178.

42 Y. Gao, Y. Li, X. Zhao, J. Hu and Y. Ju, RSC Adv., 2015, 5, 102097-102100.

43 K. Zhi, H. Zhao, X. Yang, H. Zhang, J. Wang, J. Wang and J. M. Regenstein, Nanoscale, 2018, 10, 3639-3643.

44 Y. Gao, J. Hao, J. Wu, X. Zhang, J. Hu and Y. Ju, Langmuir, 2016, 32, 1685-1692.
45 B. G. Bag and R. Majumdar, Chem. Rec., 2017, 17, 841-873. 46 Y. Gao, J. Hao, J. Wu, X. Zhang, J. Hu and Y. Ju, Nanoscale, 2015, 7, 13568-13575.

47 B. G. Bag, G. C. Maity and S. K. Dinda, Org. Lett., 2006, 8, 5457-5460.

48 B. G. Bag and S. S. Dash, RSC Adv., 2016, 6, 17290-17296.

49 E. Lepeltier, C. Bourgaux, A. Maksimenko, F. Meneau, V. Rosilio, E. Sliwinski, F. Zouhiri, D. Desmaele and P. Couvreur, Langmuir, 2014, 30, 6348-6357.

50 B. G. Bag, S. Das, S. N. Hasan and A. C. Barai, RSC Adv., 2017, 7, 18136-18143.

51 B. G. Bag, Sk N. Hasan, S. Ghorai and S. K. Panja, ACS Omega, 2019, 4, 7684-7690.

52 T. Miura, N. Ueda, K. Yamada, M. Fukushima, T. Ishida, T. Kaneko, F. Matsuyama and Y. Seino, Biol. Pharm. Bull., 2006, 29, 585-587.

53 W. Hou, Y. Li, Q. Zhang, X. Wei, A. Peng, L. Chen and Y. Wei, Phytother. Res., 2009, 23, 614-618.

54 Y. Xu, R. Ge, J. Du, H. Xin, T. Y. a., J. Sheng, Y. Wang and C. Ling, Cancer Lett., 2009, 284, 229-237.

55 C. Y. Ku, Y. R. Wang, H. Y. Lin, S. C. Lu and J. Y. Lin, PLoS One, 2015, 10, 1-17.

56 Gaussian 09®, Gaussian Inc., Wallingford CT, 2009.

57 PCModel version 9.2 Serena Software®.

58 T. Rehm, V. Stepanenko, X. Zhang, F. Wurthner, F. Grohn, K. Klein and C. Schmuck, Org. Lett., 2008, 7, 1469-1472.

59 R. Dong, W. Liu and J. Hao, Acc. Chem. Res., 2012, 45, 504513.

60 M. Yang, W. Wang, F. Yuan, X. Zhang, J. Li, F. Liang, B. He, B. Minch and G. Wegner, J. Am. Chem. Soc., 2005, 127, 15107-15111.

61 Y. Chen, A. Angelova, B. Angelov, M. Drechsler, V. M. Garamus, R. Willumeit-Römer and A. Zou, J. Mater. Chem. B, 2015, 3, 7734-7744.

62 L. Zerkoune, S. Lesieur, J. L. Putaux, L. Choisnard, A. Gèze, D. Wouessidjewe, B. Angelov, C. Vebert-Nardin, J. Doutch and A. Angelova, Soft Matter, 2016, 12, 7539-7550.

63 A. Angelova, V. M. Garamus, B. Angelov, Z. Tian, Y. Li and A. Zou, Adv. Colloid Interface Sci., 2017, 249, 331-345.

64 V. P. Torchilin, Nat. Rev. Drug Discovery, 2005, 4, 145-160.

65 R. T. Skeel and S. N. Khleif, Handbook of Cancer Chemotherapy, 2011, vol. 8, pp. 1-832.

66 B. Tian, X. Tao, T. Ren, Y. Weng, X. Lin, Y. Zhang and X. Tang, J. Mater. Chem., 2012, 22, 17404-17414.

67 P. Moitra, K. Kumar, P. Kondaiah and S. Bhattacharya, Angew. Chem., Int. Ed., 2014, 53, 1113-1117.

68 A. Ali, M. Kamra, A. Bhan, S. S. Mandal and S. Bhattacharya, Dalton Trans., 2016, 45, 9345-9353.

69 M. Jhonson, Mater. Methods, 2013, 3, 163-175.

70 F. Gennuso, Proc. Natl. Acad. Sci. U. S. A., 2004, 101, 24702475.

71 A. Rajagopal, A. C. Pant, S. M. Simon and Y. Chen, Cancer Res., 2002, 62, 391-396. 